\title{
Continuance Intention to Use Facebook: A Study of Perceived Enjoyment and TAM
}

\author{
K. Praveena and Sam Thomas
}

\begin{abstract}
The use of social networking sites has emerged rapidly as an ideal platform for social interaction. Different social networking sites are characterized according to their usage like business networking, entertainment and social interactions. Facebook, the most commonly used site for social interactions has the large number of users worldwide. This study aims to identify the continuance intention of using facebook, through an extension of the Technology Acceptance Model (TAM). TAM is one of the most useful models used for predicting user acceptance. Perceived Enjoyment was added to the TAM variables to explain the continuance intention to use Facebook. A survey method was adopted and the sample constituted students of undergraduate and post graduate courses. The results reveal that the model explains 36\% variation in the continuance intention to use Facebook. Perceived Enjoyment was seen to be a strong determinant of attitude towards using Facebook in this study.
\end{abstract}

Keywords--- Attitude, Continuance Intention, Facebook, Perceived ease of Use, Perceived Enjoyment, Perceived Usefulness

\section{INTRODUCTION}

$\mathrm{S}_{\mathrm{h}}^{\mathrm{o}}$ OCIAL NETWORKING SITES (SNS) have gained a huge popularity and growth in the last few years. The different social networking sites like Twitter, Facebook, Google Plus, MySpace etc serve different purposes and different strata of the society. Facebook has emerged as a tool for social interaction, irrespective of any differentiation in the society. Facebook is rated as the largest social networking sites in terms of number of users (socialbakers.com) and has approximately 1.15 billion total users as on June 2013. A large percentage of the young generations are active members of Facebook. The use of Facebook is not restricted as a tool of social interaction only, but also as a source for rich entertainment functions like, games, different apps and advertisement tool. Facebook, launched in 2004 was initially an attempt to connect the college students and information exchange. Facebook has been in research to study the motivations [28] [19] and usage effects [52]. The trust and privacy issues connected with Facebook have also been explored [44] [15].

Praveena K, Research Scholar, School of Management Studies, Cochin University of Science and Technology, Ernakulam, Kerala, India. E-mail : pravimurali@gmail.com

Sam Thomas, Assistant Professor, School of Management Studies, Cochin University of Science and Technology, Ernakulam, Kerala, India. E-mail : sam@cusat.ac.in

DOI: 10.9756/BIJIEMS.4794
The acceptance of information technology/systems are studied using different theoretical models like Technology Acceptance Model (TAM),Combined TAM and Theory of Planned Behavior (TPB), Innovation Diffusion Theory (IDT), Unified Theory of Acceptance and Use of Technology (UTAUT) and so on. The flow theory allows the measurement of the elements of pleasure and entertainment motivating users' continuance of Facebook [29]. The advent of numerous social networking sites with varied uses and offerings have made the competition high in the usage of these sites. The study on continuance intention to use such sites thus gains importance. The objective of the study is to explain the continuance intention to use Facebook through the Technology Acceptance Model (TAM).

The structure of the paper is as follows. Section II introduces the related literature, leading to the development of the conceptual model. Section III includes the explanation of the methodology adopted. Section IV gives a detailed discussion on the findings of the study, followed by Section V which concludes the paper.

\section{LiterATURE REVIEW}

\section{A. Social Network Sites}

Social networking websites have been defined as "web based services that allow individuals to (1) construct a public or semi-public profile within a bounded system, (2) articulate a list of other users with whom they share a connection, and (3) view and traverse their list of connections and those made by others within the system."[6]. "Social network is the label attached to any consumer-initiated communication with other consumers who share an interest and use the World Wide Web as a platform for creating a community"[42]. SNS allow people to share information, activities and interests, maintain relationships and connect with each other and log into these sites multiple times a day [21],[16]. The advent of SNSs facilitates online communities to maintain preexisting social connections and make new online friends [17]. Studies on the usage of SNSs report that SNSs are mainly used for messaging, sharing information and keeping in touch with each other [36]. The use of SNSs has now grown to being used as a marketing and business tool. The media use these sites as a promotion tool while many organizations do their business and marketing using these sites. Businesses participate in these communication channels to gather the perceptions of customers about current products and services, and get ideas about new product and service development. Facebook has been rated to have the largest number of users (Socialbakers.com). The varied entertainment functions like online games, the apps, the advertisement facilities etc. have 
made it popular, particularly among the youth. Though the initial use of Facebook was to maintain and connect with each other, the use of Facebook has now grown to a platform for varied discussions even concerning social issues.

\section{B. Continuance Intention}

According to [5], IS continuance intention (CI) is defined as an individual's intention to continue using an information system (in contrast to initial use or acceptance). The Expectation Confirmation Theory [39] was modified to suit the use of information system and the post acceptance model of information system continuance was proposed by the concept that "continuance usage intention of system will be influenced by system usage satisfaction and perceived usefulness"[5]. The continuance usage behavior was explained by adding perceived usefulness and perceived entertainment to the post acceptance model [46]. Prior studies on continuance intention include those of web based learning tools [25]; continuance intention of mobile internet services [53]. In this study, we try to explore the continuance intention to use Facebook by the users.

\section{Technology Acceptance Model (TAM)}

Technology Acceptance Model, developed by [12] is based on the Theory of Reasoned Action (TRA) [18]. TAM is the most influential and widely tested model to explain the acceptance of information technology/systems. TAM posits that Perceived Usefulness (PU) and Perceived Ease of Use (PEOU) and attitude share a causal relationship with the intention and usage behavior. TAM is known as the robust and parsimonious model to predict user's acceptance of technology [48]. Researchers always suggest the addition of external variables to TAM so that the model is strengthened more. TAM 2 was proposed by incorporating social influence and cognitive instrumental processes [48]. This model explained the usage both in mandatory and voluntary environments. TAM and extensions of TAM are widely used to explain the acceptance of different information systems/technologies such as www [1], telemedicine technology [8], broadband [27], e-learning [40], e-commerce [20], social networks [41] to name a few.

\section{Perceived Usefulness}

Perceived Usefulness (PU) is defined as the user's "subjective probability that using a specific application system will increase his or her job performance within an organizational context [12]". PU has been used in nonorganizational contexts also like internet banking [51],[31], online shopping [49], mobile services [45]. In TAM model, it is posited that PU affects the behavioral attitude and the intention to use. PU, in this study attributes to the usefulness of Facebook in maintaining relationships, connecting with people, use of different apps etc. We state the following hypotheses.

H1: There is a positive relationship between Perceived Usefulness and Attitude

H2: There is a positive relationship between Perceived Usefulness and Continuance Intention to use Facebook

Perceived Ease of Use
Perceived Ease of Use (PEOU) is defined as the "degree to which the user expects the target system to be free of efforts [12]". In this study, PEOU is considered as the degree to which a person believes that Facebook is easy to use and not much effort is required. There have been many previous researches which consistently argue the importance of PEOU in explaining the acceptance of different systems [14], [20], [48]. PEOU is also found to be positively related to PU [24], [33], [12]. TAM states that PEOU directly influences attitude and also has an indirect influence on attitude through the PU. The following hypotheses are stated.

H3: There is a positive relationship between Perceived Ease of Use and Attitude

H4: There is a positive relationship between Perceived Ease of Use and Perceived Usefulness

\section{E. Perceived Enjoyment}

Perceived Enjoyment (PE) is an intrinsic motivation that emphasizes the usage process and reflects the pleasure and enjoyment associated with the using a system. Perceived Enjoyment is found to be positively related to attitude towards using a specific source [37]. Previous studies have reported the effect of PE on user behavior [29],[13]. Enjoyment is one of the main reason people opt to use social networking sites [23]. Enjoyment in using a website significantly influences the intentions to use [26], [11]. The following hypotheses is stated

H5: There is a positive relationship between Perceived Enjoyment and Attitude

H6: There is a positive relationship between Perceived Enjoyment and Continuance Intention to use Facebook

\section{F. Attitude}

Attitude can be viewed as the degree to which an individual is favorably or unfavorably inclined towards an object [18]. Numerous researches have explored the influence of external variables on attitude [34], [12]. The behavioral intention to use a system is determined by the attitude towards using the system [12]. The mediating role of attitude in acceptance of a system has also been explored in various researches. [24], [9], [12]. According to [32], Facebook users hold the positive attitudes toward the sites. User attitude towards social networking sites mediates their perceptions and behavior [19].

H7: There is a positive relationship between attitude and continuance intention to use Facebook 
The proposed conceptual model is depicted in Figure (1)

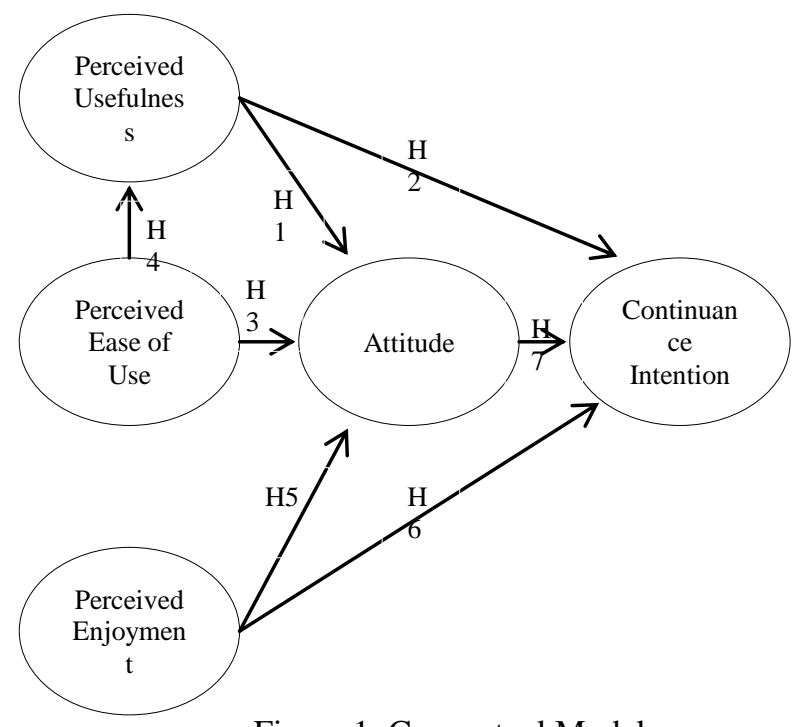

Figure 1: Conceptual Model

\section{RESEARCH METHODOLOGY}

\section{A. Sampling}

The study being an explorative one, survey method was used for collecting data. Students were chosen as respondents for the survey keeping in mind the fact that they contribute to the major percentage of users of facebook. A questionnaire was designed to collect data from students. The sample was chosen from colleges in Central Kerala. The sample constituted of students doing under graduation and post graduation courses in different colleges. Both online and offline method was used to distribute the questionnaires and collecting the responses. A total of 197 responses were collected. The sample consisted of approximately $58 \%$ males and $42 \%$ females. The average age of the respondents was 22 years. Table 1 shows the sample statistics.

TABLE I. SAMPLE STATISTICS

\begin{tabular}{|l|c|r|}
\hline & Mean & Std.Deviation \\
\hline Age & 22.23 & 1.438 \\
\hline
\end{tabular}

\begin{tabular}{|c|c|c|}
\hline Gender & Frequency & Percentage \\
\hline Male & 114 & 57.9 \\
\hline Female & 83 & 42.1 \\
\hline Total & 197 & 100 \\
\hline
\end{tabular}

\section{B. Measures of Concepts}

Constructs were measured using multiple item scales drawn from prevalidated measures in information systems use and reworded to specifically relate them to the use of Facebook. Perceived Usefulness, Perceived Ease of Use and Attitude were adapted from [12]. Items measuring Perceived Enjoyment were adapted from [29]. Measurement of Continuance intention was adapted from [35] and [5]. All the items were measured using 5 point Likert scales.
The model was tested in three stages. Reliability of the measurement tools was found at the first stage. A Confirmatory Factor Analysis (CFA) was performed to check validity of the model. This ensured the overall fit of measurement model. The third test was to check the data support for the proposed structural model and the hypotheses stated.

The reliability of measures were estimated by using Cronbach Alpha, and all the values of Cronbach alpha for the constructs satisfied the cut-off of 0.707 [38], [20]. Hence, the adequate levels of reliability for the measures were satisfied.

TABLE II. CRONBACH ALPHA VALUES

\begin{tabular}{|l|l|}
\hline Construct & Cronbach alpha \\
\hline $\begin{array}{l}\text { Perceived } \\
\text { Usefulness }\end{array}$ & 0.720 \\
\hline $\begin{array}{l}\text { Perceived Ease Of } \\
\text { Use }\end{array}$ & 0.833 \\
\hline $\begin{array}{l}\text { Perceived } \\
\text { Enjoyment }\end{array}$ & 0.843 \\
\hline Attitude & 0.840 \\
\hline $\begin{array}{l}\text { Continuance } \\
\text { Intention }\end{array}$ & 0.791 \\
\hline
\end{tabular}

\section{Data Analysis}

Structural Equation Modeling (SEM) was used to test the model. SEM is a multivariate statistical methodology, which takes a confirmatory approach to the analysis of a structural theory. SEM provides researchers with the ability to accommodate multiple interrelated dependence relationships in a single model [22],[3]. AMOS 4.0, a leading SEM package, was used for this study.

CFA is often used to confirm a factor structure known beforehand. In this study, since the constructs are known, CFA was executed to validate the model. The standardized factor loadings obtained from the measurement model (CFA) indicates that all indicators loaded to the respective factors significantly. The standardized loadings range from 0.551 to 0.872 with all $\mathrm{p}$ values $<0.01$.

The values of fit measures obtained for the model are; Goodness of Fit Index (GFI) $=0.890$; Adjusted Goodness of Fit Index (AGFI) $=0.852$; Comparative Fit Index (CFI) $=0.938$; Tucker Lewis Index $(\mathrm{TLI})=0.926$; Incremental Fit Index $(\mathrm{IFI})=0.939 ; \mathrm{RMR}=0.056$; Chi-Squared with 128 degrees of freedom, $\chi 2(128)=222.864, \mathrm{p}<0.05$ and Normed $\chi 2=1.741$. The values show an acceptable overall fit and show that the measurement model is theoretically and statistically acceptable.

The results show that Perceived Usefulness (PU), Perceived Ease of Use (PEOU) and Perceived Enjoyment (PE) have positive influence on Attitude. This supports our hypotheses $\mathrm{H} 1, \mathrm{H} 3$ and $\mathrm{H} 5$. It is seen that PU positively influences Continuance Intention and hence, $\mathrm{H} 2$ is also 
supported. Perceived Enjoyment was found to have an insignificant direct association with Continuance Intention to use Facebook and hence, H6 stands rejected. Attitude is positively associated with Continuance Intention, thus supporting our hypothesis H7.

Figure (2) shows the final model with path loading coefficients significant at 0.05 level.

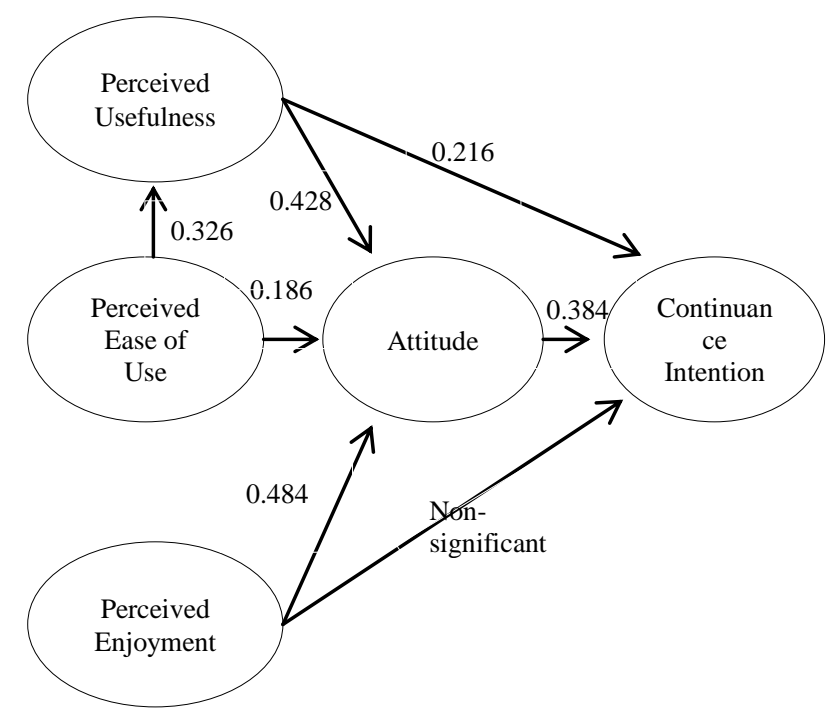

Figure 2: Path coefficients

The standardized total effects estimates shows that Perceived Enjoyment (PE) has more effect on Attitude (0.484) than those of PU (0.428) and PEOU (0.325). Thus in the case of Facebook, PE influences Attitude more than PU and PEOU. The $\mathrm{R}^{2}$ value for Continuance Intention is 0.356 , which indicates that the model explains approximately $36 \%$ variations in the "continuance intention to use Facebook".

The regression equations are as follows:

$\mathrm{PU}=0.326(\mathrm{PEOU})+\mathrm{E}$

$\mathrm{A}=0.484(\mathrm{PE})+0.428(\mathrm{PU})+0.186(\mathrm{PEOU})+\mathrm{E}$

$\mathrm{CI}=0.384(\mathrm{~A})+0.216(\mathrm{PU})+\mathrm{E}$

where, PU-Perceived Usefulness, PEOU-Perceived Ease of Use, PE-Perceived Enjoyment, A-Attitude and CI-Continuance Intention and E-Standard Error

\section{DISCUSSION}

The study was intended to explore the factors that influence the continuance intention to use Facebook, by adding the variable Perceived Enjoyment (PE) to TAM model. PE shows a significant effect on attitude while an insignificant direct effect on Continuance Intention to use Facebook. The study sample was students of mean age 22 years. The results reveal that PE acts the same as Perceived Ease of Use in the TAM model. PU was found to have a significant influence on attitude to using Facebook, while insignificant on the direct effect on continuance intention to use Facebook. The major use of Facebook by the young generation is to connect with their friends and share the happenings. With the advent of numerous sites offering such facilities, the youngsters loose the feeling on intending to continue the use of Facebook, while they strongly support the effect of usefulness in the attitude to using Facebook. This echoes the findings of [41], [30].According to [10], PU has only a moderate effect on continuance intention, in his study of online shopping.

Perceived Ease of Use (PEOU) significantly influences Attitude to use Facebook and Perceived Usefulness. This is consistent with the extant researches on TAM [7], [41], [50]. Facebook stands an easy to use site when compared with the other sites offering the same uses. The study supports the different studies that PEOU directly and indirectly influences attitude and behavioral intention through PU [12], [48], [43].

Perceived Enjoyment (PE) plays an important role in user technology acceptance [26], [11]. On explaining the acceptance of hedonic systems, PE was found to be a significant factor [47]. From the effect sizes revealed in this study, PE had the strongest effect on attitude, followed by PU and PEOU. Rather than the usefulness of Facebook, students find this as an enjoyment medium. This may be due to the different features provided by Facebook such as the different apps, reviews and online games. In this study, it is found that PE plays a significant role in determining attitude which backs the study of [37]. The effect of PE was found to be insignificant on the direct effect on continuance intention to use Facebook, thus opposing to the findings by [2], [47], [4]. Facebook caters to the needs of both entertainment and enjoyment.

The current study contributes to the validation of the extended TAM model by introducing and confirming the influence of Perceived Enjoyment as an external variable on the user's attitude to use Facebook. Continuance Intention was chosen, as the study was on the current users of facebook and hence, the intention to continue the use of facebook is more significant than the study of the behavioural intention to use the system.

\section{CONCLUSION}

The study attempted to find the effect of Perceived Enjoyment on the TAM model to explain the continuance intention to use Facebook. Perceived Enjoyment was found to have the role similar to that Perceived Ease of Use as in TAM. It was found that Perceived Enjoyment influences Attitude more than the original TAM variables- Perceived Usefulness and Perceived Ease of Use. Facebook, mainly being a hedonic website, enjoyment rules more than the other factors. The variety features provided by Facebook ensures the enjoyment of the users. Perceived Enjoyment was found to be insignificant in the continuance intention to use Facebook. Attitude was seen to be the intervening variable between the antecedents and the continuance intention, which means that all the antecedents result in the formation of a strong attitude, which leads to the continuance intention to use Facebook. Different Social networking sites compete with each other to retain the users, offering various features for entertainment, usefulness and enjoyment. 


\section{REFERENCES}

[1] R.Agarwal and J.Prasad, "The role of innovation characteristics and perceived voluntariness in the acceptance of information technologies", Decision Sciences, vol .28, no.3, pp. 557-581, 1997.

[2] T. Al-Maghrabi and C.Dennis, "What drives consumers' continuance intention to e-shopping?:Conceptual framework and managerial implications in the case of Saudi Arabia", International Journal of Retail \& Distribution Management, vol.39, no.12, pp.899-926, 2011.

[3] J.Anderson and D.Gerbing, "Structural modelling in practice: a review and recommended two-step approach", Psychological Bulletin, vol.103, no.3, pp.411-423, 1998.

[4] M.A.Atkinson and C. Kydd, "Individual characteristics associated with World Wide Web use: an empirical study of playfulness and motivation", The Database for Advances in Information Systems, vol.28, no.2, pp. 53-62, 1997.

[5] A.Bhattacherjee, "Understanding Information Systems Continuance: An Expectation-Confirmation Model", MIS Quarterly, vol.25 ,no.3, pp.351370,2001 .

[6] D.M.Boyd and N.B.Ellison, "Social Network Sites: Definition, History, and Scholarship", Journal of Computer-Mediated Communication, vol.13, no.1, pp. 210-230, 2007

[7] C.Chang, C.Yan and J. Tseng, "Perceived convenience in an extended technology acceptance model: Mobile technology and English learning for college students", Australasian Journal of Educational Technology, vol.28, no.5, pp.809-826, 2012.

[8] P.K. Chau, and P.J. Hu, "Investigating healthcare professionals' decisions to accept telemedicine technology", Information \& Management,vol. 39, no.4, pp. 297-311, 2002.

[9] P.K. Chau, and P.J. Hu, " Information technology acceptance by individual professionals", Decision Sciences, vol.32, no.4, pp.699-710, 2001.

[10] I.Claudia ," A Decomposed Model of Consumers' Intention to Continue Buying Online", Economic Insights - Trends and Challenges, vol.64, no.4, pp. 58-69, 2012.

[11] F. D. Davis, R.P.Bagozzi, and P.R. Warshaw, "Extrinsic and intrinsic motivation to use computers in the workplace", Journal of Applied Social Psychology, vol. 22, no.14 pp.1111-1132,1992.

[12] F.D.Davis," Perceived Usefulness, Perceived Ease of Use, and User Acceptance of Information Technology", MIS Quarterly, vol.13, no.3, pp. $319-340,1989$.

[13] A.Dickinger, M. Arami and D. Meyer, "The role of perceived enjoyment and social norm in the adoption of technology with network externalities", European Journal of Information Systems, vol.17, no.1, pp. 4-11, 2008.

[14] M.Dishaw and D. Strong," Extending the Technology Acceptance Model with Task-Technology Fit Constructs", Information and Management,vol. 36, no.1, pp. 9-21,1999.

[15] C.Dwyer, S.R.Hiltz and K.Passerini, "Trust and privacy concern within social networking sites:A comparison of Facebook and MySpace" Proceedings of the Thirteenth Americas Conference on Information Systems, Keystone, Colorado, pp.339, 9-12 August 2007.

[16] N.Ellison, C. Steinfeld and C. Lampe, "Spatially bounded online social networks and social capital : The role of Facebook", Proceedings of the Annual Conference of the International Communication Association. Dresden, Germany, vol.36, 2006.

[17] N.Ellison, C.Steinfield and C. Lampe," The benefits of Facebook "friends:" Social capital and college students' use of online social network sites", Journal of Computer-Mediated Communication, vol.12, pp.1143-1168, 2007.

[18] M.Fishbein and I. Ajzen," Belief, attitude, intention and behaviour: an introduction to theory and research", California.: Addison-Wesley, 1975.

[19] H.Gangadharbatla, "Facebook me: collective self-esteem, need to belong, and internet self-efficacy as predictors of the iGeneration's attitudes toward social networking sites",Journal of Interactive Advertising,vol. 8, no.2, pp. 5-15, 2008.

[20] D.Gefen and D.Straub," The relative importance of perceived ease of use in IS adoption: a study of e-commerce adoption", Journal of the Association for Information Systems, vol.1, no.8, pp. 1-28, 2000.

[21] S.Grabner-Krauter,"Web 2.0 Social Networks: The Role of Trust", Journal of Business Ethics, vol.90, no.4, pp.505-522, 2009.

[22] J.F.Hair, R.E.Anderson, R.L.Tatham and W.C. Black," Multivariate Data Analysis "(5 ed.), Prentice-Hall International, Inc., 1998.
[23] J.Hart, C.Ridley ,F. Taher., C.Sas and A. Dix," Exploring the Facebook Experience: A New Approach to Usability",Proceedings of NordiCHI, Lund,Sweden, pp. 471-474, 2008.

[24] C.L.Hsu and H.P.Lu, "Why do people play online games? An extended TAM with social influences and flow experience", Information \& Management, vol.41, no.7, pp. 853-868, 2004

[25] P.Ifinedo," Acceptance and Continuance Intention of Web-based Learning Technologies (WLT) Use Among University Students in a Baltic Country", The Electronic Journal on Information Systems in Developing Countries, vol.23, no.6, pp.1-20, 2006.

[26] M.Igbaria,T. Guimaraes and G.B. Davis, " Testing the Determinants of Microcomputer Usage via Structural Equation Model" Journal of Management Information Systems, vol.11, no.4, pp. 87-114, 1995.

[27] Z.Irani,Y. Dwivedi and M.Williams,"Understanding consumer adoption of broadband: an extension of the technology acceptance model", Journal of the Operational Research Society, vol.60, no.10, pp.13221334, 2009.

[28] A.N.Joinson, " Looking at, looking up or keeping up with people?: motives and use of facebook" Twenty-sixth annual SIGCHI conference on Human factors in computing systems, 2008.

[29] M.Koufaris, "Applying the technology acceptance model and flow theory to online consumer behavior", Information Systems Research, vol.13, no.2, pp.205-223, 2002.

[30] Y.Kuo and S.Yen," Towards an understanding of the behavioral intention to use 3G mobile value-added services", Computers in Human Behavior,vol. 25, no.1, pp. 103-110, 2009.

[31] M.Lallmahamood,"An Examination of Individual's Perceived Security and Privacy of the Internet in Malaysia and the Influence of This on Their Intention to Use E-Commerce: Using An Extension of the Technology Acceptance Model", Journal of Internet Banking and Commerce, vol.12, no.3,pp.1 2007.

[32] C.Lampe,N. Ellison and C. Steinfield ," Changes in use and perception of Facebook",Proceedings of the ACM 2008 Conference on Computer Supported Cooperative Work, NewYork: ACM, pp. 721-730, 2008.

[33] J.C.Lin and H. Lu, "Towards an understanding of the behavioural intention to use a web site" International Journal of Information Management, vol.20, no.3, pp.197-208, 2000.

[34] H.C. Lucas and V.K. Spitler," Technology use and performance: A field study of broker workstations", Decision Sciences, vol.30, no. 2, pp. 291$311,1999$.

[35] K.Mathieson," Predicting User Intentions:Comparing the Technology Acceptance Model with the Theory of Planned Behavior",Information Systems Research, vol.2, no.3, pp. 173-191,1991.

[36] M.Mital,D.Israel and S. Agarwal," Information exchange and information disclosure in social networking web sites:Mediating role of trust", The Learning Organization, vol.17, no.6, pp. 479-489, 2010.

[37] J.Moon and Y. Kim, (2001)," Extending the TAM for a World-WideWeb context",Information and Management, vol.38, no.4, pp. 217-230, 2001.

[38] J.C.Nunnally and I.H.Bernstein ,"Psychometric Theory",New York: McGraw-Hill, 1994.

[39] R. L.Oliver, " A Cognitive Model for the Antecedents and Consequences of Satisfaction", Journal of Marketing Research, vol.17, no.4, pp.460-469,1980.

[40] S. Y.Park, " An Analysis of the Technology Acceptance Model in Understanding University Students' Behavioral Intention to Use eLearning", Educational Technology \& Society, vol.12, no.3, pp. 150$162,2009$.

[41] J.C.M.R.Pinho and A.M. Soares, "Examining the technology acceptance model in the adoption of social networks", Journal of Research in Interactive Marketing, vol.5, no.2, pp. 116-129, 2011.

[42] S.Quinton and S.Harridge-March , "Relationships in online communities: the potential for marketers", Journal of Research in Interactive Marketing, vol.4, no.1, pp.59-73, 2010.

[43] T. Ramayah and J. Ignatius," Impact of perceived usefulness, perceived ease of use and perceived enjoyment on intention to shop online", ICFAI Journal of Systems Management, vol.3, no.3, pp. 36-51, 2005.

[44] L.A.Shafie,M.Mansor,N.Osman,S. Nayan and A. Maesin, "Privacy, Trust and Social Network Sites of University Students in Malaysia", Research Journal of International Studies,vol.20, pp. 154-162, 2011.

[45] N.M.Suki and N.M.Suki,"Exploring the relationship between Perceived Usefulness, Perceived ease of Use,Perceived enjoyment,Attitude and subscribers' intention towards using 3Gmobile services", Journal of Information Technology Management, vol.22, no.1, pp.1-7, 2011. 
[46] J.Y.L.Thong, S.-J.Hong, and K.Y. Tam, "The effects of post-adoption beliefs on the expectation confirmation model for information technology continuance", International Journal of Human-Computer Studies,vol. 64, no.9, pp. 799-810, 2006.

[47] van der Heijden," User Acceptance of Hedonic Information Systems", MIS Quarterly, vol.28, no.4, pp. 695-704, 2004.

[48] V.Venkatesh," Determinants of perceived ease of use: integrating control,intrinsic motivation, and emotion into the technology acceptance model", Information Systems Research, vol.11, no.4, pp. 342-365, 2000.

[49] T-L.Wang, and Y-F. Tseng, " A Study of the Effect on Trust and Attitude with Online Shopping", International Journal of Digital Society, vol.2, no.2, pp. 433-440, 2011.

[50] T.Willis, "An evaluation of the Technology Acceptance Model as a means of understanding online social networking", Graduate School Theses and Dissertations, 2008.

[51] J.W.Wu, Y.C.Chen, and L.M.Lin," Empirical evaluation of the revised end user computing acceptance model", Computers in Human Behavior, vol.23, no.1, pp. 162-174, 2004.

[52] C.Xu,S.Ryan, V.Prybutok and C. Wen, "It is not for fun: An examination of social network site usage", Information \& Management, vol.49, no.5, pp.210-217, 2012.

[53] T.Zhou," Understanding mobile Internet continuance usage from the perspectives of UTAUT and flow", Information Development, vol.27, no.3, pp. 207-218, 2011. 